\title{
Editorial
}

\section{CONSTRUCTION CLUSTER INNOVATION}

\section{David PAYNE and Leena SARVARANTA, Guest Editors}

VTT Technical Research Centre of Finland, VTT Building \& Transport, P.O. Box 1803, FIN-02044 VTT, Finland E-mail: david.payne@vtt.fi; leena.sarvaranta@vtt.fi

The theme of this special journal edition touches upon the context, subjects and agents of innovation in the construction cluster. We consider the real estate and construction industry cluster in its widest sense. The cluster includes public and private organizations as well as individuals who play a role in the use, investments, design, planning, production, managing and maintaining of built infrastructure, offices, housing, industrial and other types of buildings, building components and materials.

Construction is often considered among "traditional" sectors with a relatively low performance, where statistical indicators are used to differentiate the R\&D activity of "high tech" and "low tech" sectors ${ }^{1}$. Its level of investment in RTD is generally less than $0.5 \%$ of company turnover and participation in EU RTD programmes has been modest despite the large size and importance of the industry. However statistics are one thing and industry practice another. We should not forget that the construction sector remains economically significant, employing about $7 \%$ of the working population, contributing over $6-11 \%$ to any Nation's GDP and responsible for about $50 \%$ of fixed capital formation $^{2}$. It is an essential producer of effective living and working built environments.

1 OECD (1998) Science, Technology and Industry Outlook.

2 FIEC (2003) Construction in Europe: Key Figures.

3 Manseau and Seaden. (2001) Innovation in Construction: An International Review of Public Policies, Spon, London.
However, increasing competitive pressures and demand requirements have emerged over the last decade or so, together with impressive performance changes in other sector industries. This has led to an increased focus on innovation in construction, as recent studies testify ${ }^{3}$.

Innovation in Construction may have many forms: technologically new/improved buildings and physical infrastructures; technologically new/improved construction processes; non-technological process innovations; and non-technological improvements in the organisation of the industry. Innovations within specific construction projects may be commonplace, although is not often recognised nor the learning captured. More attention appears to be given to technological product innovation than process innovation, however innovations in the organisational and technological capabilities of the industry seem far less frequent. The field has been ripe for all manner of studies of innovation - mostly, it seems, technological.

One feature of the construction industry is the predominance of small and medium sized enterprises (SMEs), accounting for as much as 97\% of the industry in Europe, for example. This feature of the industry's structure makes the application of "traditional" R\&D originated innovations in a linear model, problematic. How would SMEs engage in such innovation, considering the resource constraints, let alone the interdependencies with related parts of a long and complex value chain? The appreciation of systemic and open innovation "processes", together with an understanding of in- 
novation on a business's own terms has helped. A recently completed European project, $(\text { CONSTRINNONET })^{4}$, has focused on such issues and provides some of the contributions to this journal edition.

In the paper by Dick \& Payne, the industry at European level is reviewed and the support for innovation at regional level is addressed; this is an important consideration in view of the fact that the majority of construction SMEs operate in a regional context. The related aspects of clusters and networks in which an individual firm is situated forms the basis for Garcia's paper, which points to the wider implications for policy. Abbott \& Allen's paper provides an excellent case study of an organisation working "on the ground" in support of innovation in the construction cluster, providing colour and example to subjects of the preceding papers.

Emerging societal needs, which contribute to the user-demand side for new innovations is well demonstrated in the paper by Koukkari $\&$ Sarvaranta. They consider new types of services and networks and the potential of ICT, in facing the challenges of an ageing population and ageing infrastructure.

The proliferation of technologies brings challenges too. The need of suppliers and customers to choose the best options for materials, equipment or facilities presents challenges, especially when there are many factors to consider in making a choice. This forms the subject for the paper by Zavadskas et al., who describe models for the basis of an innovation in decision-making systems.

All of the papers in this journal edition point to the significance and some of the possibilities for innovation; this is but a small drop in the broad construction cluster, where countless innovations are possible. We would like to thank all the referees for their contribution to this special issue. Papers have been seriously reviewed.

\footnotetext{
4 Wharton \& Payne. (2003) Promoting innovation in construction SMEs: an EU case study, UNEP/DTIE, Vol. 26, No $2-3$.
} 